\title{
Decomposition of spontaneous fluctuations in tumour oxygenation using BOLD MRI and independent component analysis
}

Miguel R Gonçalves, S Peter Johnson, Rajiv Ramasawmy, R Barbara Pedley, Mark F Lythgoe and Simon Walker-Samuel

Correction to: British Journal of Cancer (2015) 113, 1168-1177. doi:10.1038/bjc.2015.270; published online 20 October 2015

Updated online 26 May 2016: This article was originally published under a CC BY-NC-SA 4.0 license, but has now been made available under a CC BY 4.0 license. The PDF and HTML versions of the paper have been modified accordingly. (c) (i) This work is licensed under the Creative Commons Attribution 4.0 International License. To view a copy of this license, visit http://creativecommons.org/licenses/by/4.0/ 